\title{
A 17-year longitudinal study of religion and mental health in a Mormon sample
}

Jeremy D. Bartz

Brigham Young University, jeremybartz@gmail.com

P. Scott Richards

Brigham Young University, scott_richards@byu.edu

Timothy B. Smith

Brigham Young University, tbs@byu.edu

Lane Fischer

Brigham Young University, lane_fischer@byu.edu

Follow this and additional works at: https://scholarsarchive.byu.edu/facpub

Part of the Counseling Psychology Commons, and the Mormon Studies Commons

\section{Original Publication Citation}

Bartz, J. D., Richards, P. S., Smith, T. B., \& Fischer, L. (2010). A 17-year longitudinal study of religion and mental health in a Mormon sample. Mental Health, Religion, \& Culture, 13, 683-695.

\section{BYU ScholarsArchive Citation}

Bartz, Jeremy D.; Richards, P. Scott; Smith, Timothy B.; and Fischer, Lane, "A 17-year longitudinal study of religion and mental health in a Mormon sample" (2011). Faculty Publications. 2032.

https://scholarsarchive.byu.edu/facpub/2032 
Bartz, J. D., Richards, P. S., Smith, T. B., \& Fischer, L. (2010). A 17-year longitudinal study of religion and mental health in a Mormon sample. Mental Health, Religion, \& Culture, 13, 683695.

A 17-Year Longitudinal Study of Religion and Mental Health:

Implications for Counseling and Psychotherapy 


\begin{abstract}
In 1984, 1987 and 2001 data were collected on a religiously devout group of college students in an effort to better understand the process of religious development and the relationship between religiosity and mental health. This study analyzes that data by examining the relationship between devoutness and psychopathology over time, the correlations between intrinsic religiosity and scores of psychopathology, the stability of religious motivations over the course of adulthood, and the stability of two different religious development styles that were identified in 1984. This study found that (1) these religiously devout individuals have consistently fallen within the normal range on the clinical scales of the Minnesota Multiphasic Personality Inventory and have demonstrated continual reduction in their scores on those scales, (2) there were no correlations between scores of intrinsic religiosity and psychopathology, (3) these participants' religious motivations remained stable over the course of adulthood, and (4) most of the participants eventually manifested a continuous style of religious development. Implications for counseling practice are discussed.
\end{abstract}


A 17-Year Longitudinal Study of Religion and Mental Health: Implications for Counseling and Psychotherapy

In response to criticisms that religious devoutness and orthodoxy are associated with emotional disturbance (Ellis, 1980; Freud, 1928), a longitudinal study was initiated in the early 1980s to explore the relationship between devout religious lifestyles, personality development, and mental health (Bergin, Stinchfield, Gaskin, Masters, \& Sullivan, 1988). Sixty undergraduate students at a religious university in the western United States participated in the study. They completed a battery of psychological tests, provided their life histories, and participated in a semi-structured interview conducted by members of the research team. The researchers found that their sample of young adults was religiously intrinsic or devout and that they were no more likely than the general population to be at risk for psychopathology as measured by the Minnesota Multiphasic Personality Inventory (MMPI).

Some insight was also gained into the processes of spiritual development in young adults. For example, 44 of the research participants experienced a “continuous” development style where their identification with family and church values progressed smoothly into young adulthood and contributed to healthy personality functioning. Sixteen others experienced a “discontinuous” developmental style that was characterized by significant fluctuations in religious involvement and personality functioning over their lives. Some implications for counseling practice were offered by the researchers. In 1987 a follow-up study was conducted on the same participants (Bergin et. al, 1994), which provided further evidence that devout religious lifestyles were associated with positive mental health.

During the two decades since these studies were conducted, hundreds of additional studies have investigated the relationships between religion and various dimensions of mental 
and physical health. Overall, the findings have not supported the religiosity-emotional disturbance hypothesis (Gartner, Larson, \& Allen, 1991; Koenig, 1998a; Koenig, McCullough, \& Larson, 2000; Payne, Bergin, Bielema, \& Jenkins, 1991; Plante \& Sherman, 2001). In a comprehensive review of this literature, Koenig, McCullough and Larson (2001) concluded that that some forms of religion and spirituality are positively associated with many indicators of both physical and mental health, including greater happiness, life satisfaction, hope, personal control, marital satisfaction, positive social conduct, and less depression, anxiety, and suicidal behavior and ideation. In particular, devout intrinsic religiousness has consistently been shown to be associated with better psychological functioning (Bergin, 1983; Gartner et al., 1991). These findings and other positive findings have contributed to a reevaluation of the role of religious and spiritual beliefs in psychotherapy. A majority of mainstream mental health professionals now consider such beliefs and behaviors to be resources for promoting therapeutic change rather than simply as a neurosis or irrationality (Bergin, 1991; Miller, 1999; Richards \& Bergin, 2005;

Shafranske, 1996; Sperry \& Shafranske, 2005).

Despite these findings and changes in professional attitudes towards religion, it needs to be acknowledged that not all of the empirical findings show positive relationships between religion and psychological functioning. For example, extrinsic religiousness has been found to be uncorrelated or negatively correlated with healthy psychological functioning (Bergin, 1983; Koenig et al., 2001; Richards \& Bergin, 1997). One study found that religiousness is positively correlated with severity of obsessive-compulsive disorder (Koenig et al, 2001). Pargament (1997) concluded that among the various different styles of religious coping, several are actually harmful to mental heath (1997). For example, interpretation of negative events as punishments from God is related to negative mood and negative assessments of how well the events have been 
resolved. Larson et al (1991) concluded that religion is associated with several variables that may be related to poorer social and emotional functioning, including dependency, lower levels of self-actualization, rigidity, dogmatism, and authoritarianism.

Overall the empirical evidence on the relationship of spiritual and religious variables with serious mental illness, such as major affective disorders, personality disorders, eating disorders, schizophrenia and other psychotic disorders is dramatically less abundant than on other types of functioning such as life satisfaction and subjective well-being, social conduct, and physical health. Few comparisons have been made of truly pathological versus nonpathological groups, and insufficient data are available showing rates of specific clinical disturbances within samples of specific religious denominations (Payne, Bergin, Bielema, \& Jenkins, 1991). Judd’s (1999) review of Minnesota Multiphasic Personality Inventory data from studies of many religious groups showed normal mean profiles and no differences across mainstream denominations in the United States. However, significant as this finding is, the studies reviewed by Judd were crosssectional in nature, giving us only a snap shot view of the relationship between MMPI scores and religious affiliation.

Despite the large amount of research that has been done concerning religion, spirituality and mental health, the findings in this domain are still limited in some ways. Because most research studies on religion and its relationship to mental health variables have been limited to correlational and cross-sectional designs (Duke \& Johnson, 1998; Fowler, 1981), longitudinal studies are especially needed. Larson, Swyers, \& McCullough (1997) pointed out the dearth of longitudinal studies in this domain and identified such studies as a priority for the future. Longitudinal studies could help shed light on some of the discrepancies in the research findings as well as help establish whether observed relationships are causal in nature. 
To date no studies that we are aware of have examined the relationship between religious devoutness and psychopathology as measured by the MMPI over the course of adulthood. In addition, very little is known about the stability of intrinsic and extrinsic religiousness over the course of adulthood - two ways of being religious that have often been positively or negatively associated with psychological functioning. Finally, no studies have been performed to examine the stability of the continuous and discontinuous religious developmental styles over time.

In an effort to help address these deficiencies in the literature, in 2001 we recollected data on the original participants of Bergin's study. The general purpose of this follow-up study was to investigate the relationship between devoutness and mental health over time, the stability of religious motivations over the course of adulthood, and the stability of the religious developmental styles identified in 1984 and to consider the implications of these findings for psychological practice. Specifically, the following research questions were addressed: (1) Have the MMPI scores for the participants remained within the normal range for adults over the course of the study? (2) Have the MMPI scores for the participants changed over the course of adulthood and if so how? (3) What are the correlations between intrinsic religious motivations and the clinical scales of the MMPI for the participants at the three times of data collection? (4) Have the religious motivations (i.e., intrinsic/extrinsic religiousness) of the participants remained stable over time? (5) Are the continuous and discontinuous styles of religious development stable over the course of adulthood?

\section{Methods}

\section{Participants}

The original sample was composed of 60 undergraduate dormitory residents (27 men and 33 women) who regularly attended a student ward of The Church of Jesus Christ of Latter-day 
Saints (Ulrich, Richards, \& Bergin, 2000). The median age of the participants at the onset of the study was between 18 and 19 years. For the most part the participants came from White, middleclass families living in urban areas; all of them were single. Half came from Western states and the other half came from 15 other states, Canada, and West Germany. They had an average high school grade point average of 3.51 .

At the time of the original study in 1984, most of the participants were markedly intrinsic in their religious orientation and very involved in their church community. Most of them gave much time to voluntary church service and donated sizable amounts of income to religious and humanitarian purposes. Between the first and the second study in 1987, more than half of the participants served two-year full-time church missions.

At the time of the third follow-up the sample was characterized by the following educational, socio-economic, career and religious demographics. The median age of the participants was between 35 and 36 years. Twenty-five of the participants were male and twentyeight were female. Eighty-one percent of them were married, 5 of the participants never married and 5 were divorced. Of those participants with children the range varied from one to eight with the modal number being two. The modal income of the sample was between $\$ 35,000-\$ 50,000$ and the median income was between $\$ 60,000-\$ 70,000$. The grand majority of the participants remained religious devout according to their life chart reports. In 2001 most of the participants were still markedly intrinsic in their religious orientation — the mean of the ROS scores being 38.42. Ninety-six percent were still Latter-Day Saints, one had no religious affiliation and one was Lutheran. Ninety percent of the sample attended church weekly; three participants attended most of the time and one participant attended twice a year. On average the sample participants provided 5.7 hours a week to church service. In 2001 data were collected on 53 of the original 60 
participants due to the fact one had serious health problems, one had passed away and several others were unable to be located or declined. Among the 53 participants that did provide followup data some of them failed to complete specific instruments, therefore, the samples varied slightly from one analysis to another.

\section{Measures}

Consistent with the previous studies participants have been administered a test battery consisting of a biographical inventory, the MMPI-2, the Religious Orientation Scale (Allport \& Ross, 1967), life charts where participants charted the trajectories of their closeness to God, church, and emotional well-being over their life span. The MMPI-2 is the most widely used and widely researched test of adult psychopathology. It is used by clinicians to assist with the diagnosis of mental disorders and the selection of appropriate treatment methods. It has demonstrated good reliability and validity in assessing major symptoms of social and personal maladjustment (Butcher \& Williams, 2000). The Religious Orientation Scale (ROS) developed by Allport and Ross (1967) measures the degree to which a person's religious life is motivated by intrinsic and extrinsic motivations. The ROS may be the most widely used measure of religious orientation and despite some psychometric problems with the extrinsic scale and some theoretical concerns concerning what it actually measures, it has demonstrated its usefulness as a general measure of religious devoutness or commitment in hundreds of studies (Hill \& Hood, 1999).

Interviews

Using a semi-structured interview guide, members of the research team interviewed each participant for two hours. The interviews revealed a range of information, including some details about each person's life history, values, lifestyle, personal conflicts, life challenges and religious 
and spiritual experiences. The main goal of these interviews was to gain insight into the participants' level of religious commitment during their lives so far and in what ways they perceive that their religious involvement and spiritual experiences have contributed to or detracted from their mental health and psychospiritual functioning. All of these interviews were transcribed for analysis.

\section{Coding Religious Development Styles}

To address the question of whether the participants’ religious development style remained stable over time or had changed it was necessary to reclassify the participants into religious development styles based on the information collected about them in 2001. The participants were recoded according to the following criteria. If the participants' interviews demonstrated any one of following, either more than one serious deviations from church standards or more than one "turning point" or one deviation and one turning point, then their transcripts were to be coded as discontinuous, otherwise they were to be coded as continuous. If the life charts demonstrated more than one dip of half an inch or more then the charts were to be coded as discontinuous, otherwise they were to be coded as continuous. If the interview code did not coincide with the life chart code then coders were to default to the clearest, most salient code for the final participant code. After the coders had become familiar with the difference between the two styles of religious development, an analysis was performed on the 2001 life charts to identify which individuals had demonstrated continuous vs. discontinuous styles since 1984 . These codes were cross validated by examining participants' interview transcripts. Coders made final decisions consensually. 
Results

To determine whether the MMPI scores for the participants fell within the normal range for adults in 2001, a chi-square goodness of fit test was calculated on the 2001 data to determine whether the observed proportion of participants in the clinical range $(T \geq 65)$ matched the expected proportion in that range from the normative sample (i.e., eight percent [Butcher \& Williams, 2000, p. 7]). As can be seen in Table 1, no significant deviation from what would be expected in the normal population was found for scales 1 , 2, 3, 4, 6, or $7(p<.05)$. Scales 8 (schizophrenia) and 9 (hypomania) had zero participants in the clinical range, making them impossible to analyze with chi-square, so the analogous $z$ test was run on those scales. Those $z$ tests detected significantly fewer participants in the clinical range than what would be expected in the normal population $(z=-2.13, \mathrm{p}<.05)$. This finding suggests that this sample of religiously devout individuals has no more psychopathology (as measured by scales 1, 2, 3, 4, 6 \&7) than normal samples, and has even less psychopathology (as measured by scales 8 \& 9) than normal samples.

Because the analyses presented in Table 1 for the 2001 MMPI-2 data were not conducted or reported when the 1984 and 1987 data were published (Bergin et al., 1988; Bergin et al., 1994), chi-square goodness of fit tests were calculated on the 1984 and 1987 MMPI data to determine if the observed proportion of participants in clinical range $(T \geq 70)$ matched the expected proportion in that range from the normative sample (i.e. five percent [Butcher, 1994]). The cut off of 70 and the proportion of five percent were applied to the data collected using the original MMPI because those are the psychometric norms that have traditionally been used with that instrument (Butcher, 1994). No significant deviation from what would be expected in the normal population was found on the 1984 data for scales 1, 2, 3, 4, 6, or 7 ( $p>.05)$. Scales 8 
(schizophrenia) and 9 (hypomania) had significantly more participants than what would be expected in the MMPI normative sample. Elevated scores on scale nine are common for young adults. It is also common for younger participants to have higher scores on scale F. In this sample a ten point drop occurred between 1984 and 2001 on scale F. Since scale eight is responsive to scale F, this sample's elevated scale eight scores may be a function of their scale F scores. The 1987 data demonstrated no significant deviation from what would be expected in the normal population was found for scales $1,2,3,4,6,7$, 8 or $9(p>.05)$. Thus, in 1987, the proportions of participants' scores in the clinical range on scales eight and nine had decreased to what we would expect to observe in the normal population.

To determine how the sample changed in terms of psychopathology over the course of the study, one-way repeated measures ANOVAs were run on MMPI scales 1, 2, 3, 4, 6, 7, 8, 9 and F. As can be seen in Table 2, all but two of the scales demonstrated main effects in the negative direction. These main effects indicate that participants' scores significantly improved (decreased) between the years of 1984 and 2001 on scales 3, 4, 6, 7, 8, 9, and F. Scale 2 demonstrated a main effect in the positive direction. This indicates that participant's scores significantly worsened between the years of 1984 and 2001 on scale two. It should be noted that this worsening took place well below the clinical cut off $(1984$ mean $=47.52,1987$ mean $=$ 50.65, 2001 mean $=51.31$.

To determine whether the correlations between intrinsic religious motivations and the clinical scales of the MMPI remained consistent over the course of the study, Pearson correlation analyses between the ROS and MMPI scales 1-4 and 6-9 were run for the 1984, 1987, and 2001 data. Since numerous Pearson’s correlations were performed a Bonferoni correction was done in order to protect against Type I error. MMPI scales 5 and 0 were not included in the analyses 
because these scales are not by themselves measures of mental disturbance. As can be seen in Table 3, weak correlations that were not statistically significant were observed on all of the clinical scales. The negative correlations ranged from -.009 to -.323 and the positive correlations ranged from .007 to .166 . This indicates that intrinsic religiousness is not consistently or significantly associated with psychopathology as measured by the clinical scales of the MMPI in this sample of devout Latter-day Saint adults.

To determine whether the participants’ religious motivations (extrinsic and intrinsic) remained stable over the course of adulthood, a one-way repeated measures ANOVA was calculated comparing the extrinsic scores of participants at three different times: 1984, 1987, and 2001. No significant effect was found $(F(2,104)=.974, \mathrm{p}>.05)$, which indicates that there were no significant differences on the participants' extrinsic scores at 1984, 1987 and 2001. A oneway repeated measures ANOVA was calculated comparing the intrinsic scores of participants at three different times: 1984, 1987, and 2001. No significant effect was found $(F(2,104)=1.71$, $\mathrm{p}$ $>$.05), which indicates that there were no significant differences on the participants' intrinsic scores at 1984, 1987 and 2001. These results are presented in Table 4. Thus, the repeated measures ANOVAs indicate that the religious motivations for these Latter-day Saint adults remained stable from 1984 to 1987 to 2001 . The distribution of intrinsic religiosity scores in this sample approximated the normal curve with respect to skew, however; there was restriction of range indicative of a leptokurtic distribution.

Table 5 presents the results of the correlation between the religious development codes for 1984 and 2001. A phi coefficient was calculated examining the relationship between participants’ 1984 religious code types and their 2001 religious code types. The correlation between 1984 and 2001 code types was not statistically significant (phi $=.139, \mathrm{p}>.05)$. This 
indicates that participants’ 1984 code types are not significantly related to their 2001 code types. Thus, overall the code types did not remain consistent from 1984 to 2001.

Ten of the 14 participants who were coded as discontinuous in 1984 were coded as continuous in 2001. Thus, most individuals that were coded as discontinuous in early adulthood became continuous later in life. Six of the 37 participants who were coded as continuous in 1984 were coded as discontinuous in 2001. Thirty-one participants who were coded as continuous in 1984 remained continuous in 2001. Thus, most of those who were coded as continuous early in life remained continuous. It appears that the continuous religious lifestyle is relatively stable during early to mid-adulthood, but that a discontinuous religious lifestyle in early adulthood may not be predictive of such a lifestyle later in life.

\section{Discussion}

The finding that this devout sample has consistently been in the normal range on the MMPI clinical scales and that their scores have continually decreased from 1984 to 2001 on most of those scales is a longitudinal refutation of the claims that religion is deleterious to mental health (Ellis, 1980, Freud, 1928). If it were true that religious devoutness leads to psychopathology we would have expected a higher proportion of this devout sample to fall into the clinical range on the MMPI scales. We also would have expected to see to that proportion increase over time as the sample remained devout. However, the opposite was observed. This sample has consistently been similar to normal samples in spite of their devoutness. In addition, rather than becoming more pathological over time, the proportion of individuals that have fallen in the clinical range have continually decreased, furthermore this samples' scores on most measures of psychopathology have continually decreased over the 17 year course of the study. 
This finding concurs with previous research suggesting that religion is not psychologically harmful and in some cases may promote psychological health. For example, Gartner's review of the literature found that, the large majority of research suggests that religiosity is associated with lower levels of depression (1991). In Koenig, McCullough, and Larson's review of the literature in 2001 it was found that most evidence indicates that religion, especially intrinsic religiousness, tends to protect against anxiety. They also found that many studies demonstrate that religiousness is not correlated with schizotypal or psychotic thinking and that some studies show a negative correlation between the two.

Correspondingly this study demonstrated that the correlations between participants' intrinsic religious motivations and their MMPI clinical scores were consistently non-significant. This finding is consistent with other studies that have found non-significant correlations between religiosity and the MMPI (Bohrnstedt, Borgatta, \& Evans, 1968; Broen, 1955). The consistency of these findings over the course of 17 years suggests that the previous findings were not just a function of cross-sectional confounds.

The finding that the religious motivations of this sample remained stable over the course of adulthood sheds additional light on the process of religious development, indicating that religious motivations may remain fairly stable over the course of adulthood. Specifically devout individuals that are intrinsic in early adulthood may maintain that motivational style into midadulthood. The extrinsic scale was included in this analysis in spite of its poor internal consistency in order to keep this study consistent with the 1987 follow-up. The finding that this sample is still highly intrinsic is consistent with past studies of young Latter-day Saint samples (Bergin, Masters \& Richards, 1987). 
It also indicates that this sample's high intrinsic scores were not just a function of their experience attending a highly religious university where religion permeates many aspects of students’ academic and social lives. This longitudinal finding also helps to rule out the hypothesis that the participants' initial intrinsic scores were high due to the high levels of social desirability that would likely be present in an environment that rewards religious devoutness. It is unlikely that these results have been confounded by a ceiling effect because the mean intrinsic scores for 1984, 1987 and 2001 were 38.00, 39.32, and 38.42 respectively, which is below the highest possible intrinsic score of 45 . It would be helpful to replicate this analysis on other religious groups so that we could more confidently generalize across religious populations.

The finding that religiously continuous young adults tend to remain continuous into midadulthood, while religiously discontinuous individuals tend to become more continuous is an interesting extension of Bergin et al's (1988) original findings. In spite of the fact that the phi was non-significant, suggesting poor consistency between the 1984 code types and the 2001 code types, overall 35 of the 51 participants were coded identically in 1984 and 2001. Thus, for the majority of participants the code types remain stable. The discontinuous code type does not appear to be stable over the course of adulthood, but rather, most individuals coded as discontinuous in adolescence were coded as continuous in middle adulthood. This is consistent with surveys studies that suggest that disengagement from religion is more common among younger people, “especially those in their late teens and early 20’s” (Hood, Spilka, Hunsberger \& Gorsuch, 1996, p. 100).

One might speculate that individuals are more likely to experience fluctuations in their religiousness during adolescence due to lack of identity development and the process of individuation. As individuals complete the moratorium stage of identity development (Marcia, 
1966) and establish a more stable sense of who they are and what they value, it may stabilize their religious development. Hood et al (1996) suggested that the disengagement from religion that is common during adolescence, "may simply represent youthful exploration of alternative ideas and religions” (p. 101). In addition, most of the individuals in this study had started families since the first data collection in 1984. It is possible that the influence of these participants' spouses may be partially responsible for the shift from discontinuous to continuous religious development. In 1988 Stott found a strong positive reciprocal relationship between the participants’ adult religious involvement and their spouse’s religiosity. In contrast, parents’ religious involvement was only weakly correlated with participants' adult religious involvement.

\section{Limitations}

One limitation to this study involves the methodology by which the individuals were coded into religious development styles (continuous and discontinuous) in 2001. The original researchers did not leave detailed instructions explaining how they coded the participants. The coding criteria were extrapolated from recollections of one of the original researchers and an analysis of the 1984 interviews and life charts. If there was any error in this extrapolation process it may have confounded the 2001 coding. However, we have reason to believe the participants were coded in 2001 using a similar method to that of 1984. In addition, this limitation only influences the findings of research questions one, four and five.

This sample was limited to a very unique subgroup of the population. Virtually all of the participants were college students, Mormon, altruistic, white, family-oriented, and highly intrinsic. The finding that devoutness is not associated with greater risk of psychopathology may be a function of any of these unique characteristics of the sample. It is also important to note that due to these unique characteristics the generalizability of these results is limited. The 
generalizability of the results of this study is also limited by the ethnicity, socio-economic status, and the level of education of the participants. However, in spite of this limitation the nature of this sample was appropriate for answering the central question-is religious devoutness associated with mental health or illness over the course of adulthood?

Implications for Clinical Practice

The results of this study underscore the importance of not assuming that religious devoutness is necessarily a source of psychopathology. This longitudinal study supports the notion that religious beliefs and practices may actually be resources that can be utilized to facilitate healing. Several scholars have discussed how clients' religious beliefs and spirituality may be used in therapy to help promote therapeutic change (Miller, 1999; Richards \& Bergin, 2005; Richards, Hardman, \& Berrett, 2007; Sperry \& Shafranske, 2005). Richards and Bergin (2005) have recommended assessing several religious/spiritual dimensions of clients' lives including: worldview, affiliation, orthodoxy, religious problem solving style, spiritual identity, God image, value-lifestyle congruence, doctrinal knowledge, spiritual maturity, and openness to spiritual interventions. Such assessments can help clinicians determine what role religion and spirituality plays in their clients' lives; namely, is it a positive influence and potential resource during treatment, is it an unhealthy influence and contributing to clients presenting problems, or both? Once a careful religious and spiritual assessment has been conducted then clinicians are in a better position to determine whether religious and spiritual interventions might be helpful during the treatment process.

Some of the major spiritual interventions that have been advocated in the literature include: mindfulness and meditation (Marlatt \& Kristeller, 1999), prayer (McCullough \& Larson, 1999), forgiveness (Worthington, Mazzeo \& Canter, 2005), religious bibliotherapy (Richards \& 
Bergin, 2005), and cognitive-spiritual restructuring (Nielsen, Johnson \& Ellis, 2001). There is growing empirical evidence supporting the effectiveness of such spiritual approaches. For example, a recent meta-analysis of 31 outcome studies involving spirituality oriented psychotherapies provided some empirical evidence that spiritually-oriented approaches to psychotherapy are effective with religious clients (Smith, Bartz, \& Richards, in press). We refer readers to other sources for more information about the use of religious and spiritual interventions in clinical practice (Miller, 1999; Richards \& Bergin, 2005; Richards, Hardman, \& Berrett, 2007; Shafranske, 1996; Sperry \& Shafranske, 2005).

\section{Recommendations for Future Research}

In future studies it would be interesting to investigate the effect of other types of devoutness such as religious orthodoxy, fundamentalism, etc. Some versions of devoutness may be healthier than others. In addition, longitudinal studies with larger sample sizes, participants from additional religious traditions, ethnic backgrounds, socio-economic statuses, and levels of education would help to further address the questions examined in this study.

\section{Summary and Conclusions}

The most significant result of this study is that it provides longitudinal support for the notion that religious devoutness is not necessarily deleterious to mental health. This study joins with many other studies that have the hypothesis that religious devoutness is associated with poorer mental health. This study is important because it is one of the few studies that have examined this issue in a longitudinal manner over a very long period of time. This study also provided evidence that religious motivations (i.e., intrinsic and extrinsic) may remain stable during early to mid-adulthood. The findings of the current study also indicate that the continuous 
religious development type appears to be a relatively stable pattern of development during adulthood. 


\section{References}

Allport, G. W., \& Ross, J.M. (1967). Personal religious orientation and prejudice. Journal of Personality and Social Psychology, 5, 434-443.

Batson, C. D., Schoenrade, P., \& Ventis, W. C. (1993). Religion and the individual: A social-psychological perspective. New York: Oxford University Press.

Benson, P. L. Roehlkepartain, E. C. \& Rude, S. P. (2003). Spiritual Development in Childhood and Adolescence: Toward a Field of Inquiry. Applied Developmental Science 7(3) 205-213.

Bergin, A.E., Masters, K.S., \& Richards, P. S. (1987). Religiousness and mental health reconsidered: A study of an intrinsically religious sample. Journal of Counseling Psychology, 34, 197-204.

Bergin, A. E., Masters, K. S., Stinchfield, R. D., Gaskin, T. A., Sullivan, C. E., Reynolds, E. M., \& Greaves, D. (1994). Religious life-styles and mental health. In L.B. Brown (Ed.), Religion, personality, and mental health. (pp. 69-93). New York: Spinger-Verlag.

Bergin, A. E., Stinchfield, R. D., Gaskin, T. A., Masters, K. S., \& Sullivan, C. E. (1988). Religious life styles and mental health: An exploratory study. Journal of Counseling Psychology, 35, 91-98.

Bohrnstedt, G. W., Borgatta, E. F., Evans, R. R. Religious affiliation, religiosity, and MMPI scores. Journal for the Scientific Study of Religion, 7(2), 255-258.

Broen, W. E. (1955). Personality of certain religious attitudes, Journal of Consulting Psychology, 19(1), 64.

Butcher, J. N. (1994). The clinical significance level of MMPI-2. In J. N. Butcher \& J. R. Graham (Eds), Topics in MMPI-2 \& MMPI-A interpretation. (pp. 11-16). MN: University of Minnesota. 
Butcher, J. N. \& Williams, C. L. (2000). Essentials of MMPI-2 and MMPI-A

Interpretation (2 ${ }^{\text {nd }}$ ed.). Minneapolis: University of Minnesota Press.

Clinebell, H. (1995). Counseling and spiritually empowered wholeness. New York: Haworth Pastoral Press.

Duke, J. T. \& Johnson, B. L. (1998). The religiosity of Mormon men and women through the life cycle. In J. T. Duke (Ed), Latter-day Saint social life.

Ellis, A. (1980). Psychotherapy and atheistic values: A response to A. E. Bergin’s

“Psychotherapy and religious values.” Journal of Consulting and Clinical Psychology, 48, 635-639.

Fischer, L. \& Richards, P. S. (1998). Religion and Guilt. In Guilt and children. (Ed.) Jane Bybee

Fowler, J. W. (1981). Stages of faith. New York: Harper and Row.

Frame, M. W. (2003). Integrating religion and spirituality into counseling: a comprehensive approach. Pacific Grove, CA: Thomson Books/Cole.

Freud, S. (1928). The future of an illusion. Honolulu, HI: Hogarth Press.

Gartner, J., Larson, D. B., \& Allen, G. D. (1991). Religious commitment and mental health: A review of the empirical literature. Journal of Psychology and Theology, $19,6-25$

Genia, V. (1990). Religious development a synthesis and reformulation. Journal of Religion and Health. 29(2), 85-97.

Hood, R. W., Spilka, B., Hunsberger, B. \& Gorsuch, R. (1996). The psychology of religion. New York: The Guilford Press.

Judd, D. K. (1999). Religious affiliation and mental health. In Religion, Mental Health, a and the Latter-day Saints. (Ed) Daniel K. Judd. Religious Studies Center Brigham Young University: Provo, UT. 
Kass, J. D. \& Lennox, S. (2005). Emerging models of spiritual development: a foundation for mature, moral, and health promoting behavior. In Judeo-Christian perspectives on psychology : human nature, motivation, and change (Eds) William R. Miller and Harold D. Delaney.

Kirkpatrick, L. E. \& Hood, R. W. (1990). Intrinsic extrinsic religious orientation: the boon or bane of contemporary psychology of religion? Journal for the Scientific Study of Religion, 29(4), 442-462.

Koenig, H.G. (1997). Is religion good for your health? The effects of religion on physical and mental health. New York: Haworth Press.

Koenig, H.G., McCullough, M.E., \& Larson, D. B. (2001). Handbook of religion and health. New York: Oxford University Press.

Larson, D. B., Swyers, J. P., \& McCullough, M. E. (1998). Scientific research on spirituality and health: A consensus report. National Institute for Healthcare Research: Rockville, MD.

Marcia, J. E. (1966). ‘Development and Validation of Ego-Identity Status', Journal of Personality and Social Psychology, 3, 551-8.

Marlatt, G. A. \& Kristeller, J. L. (1999). Mindfulness and meditation. In W. R. Miller (Ed.), Integrating Spirituality into Treatment. (pp. 67-84). American Psychological Association: Washington, DC.

McCullough, M. E., \& Larson, D. B. (1999). Prayer. In W. R. Miller (Ed.), Integrating Spirituality into Treatment. (pp. 85-110). American Psychological Association: Washington, DC.

Miller, W. R. (1999). Integrating spirituality into treatment. American Psychological Association: Washington, DC. 
Nielson, S. L., Johnson, W. B., \& Ellis, A. (2001). Counseling and psychotherapy with religious persons: A rational emotive behavior therapy approach. Lawrence Erlbaum Associates: Mahwah, NJ.

Pargament, K. I. (1997). The psychology of religion and coping. The Guilford Press: New York, NY.

Payne, I. R., Bergin, A. E., Bielema, K. A., \& Jenkins, P. H. (1991). Review of religion and mental health: Prevention and the enhancement of psychosocial functioning. Prevention in Human Services, 9, 11-40.

Richards P. S. \& Bergin, A. E. (2005). A Spiritual strategy for counseling and psychotherapy ( $2^{\text {nd }}$ ed). American Psychological Association: Washington, DC.

Richards, P. S., Hardman, R. K., \& Berrett, M. E. (2007). Spiritual approaches in the treatment of women with eating disorders . American Psychological Association: Washington, DC.

Smith, T. B., Bartz, J. D., \& Richards, P. S. (in press). Outcomes of religious and spiritual adaptations to psychotherapy: A meta-analytic review. Psychotherapy Research.

Sperry, L. \& Shafranske, E. P. (2005). Spiritually oriented psychotherapy. American Psychological Association: Washington, DC.

Shafranske, E. P. (Ed.). (1996). Religion and the clinical practice of psychology. Washington, DC: American Psychological Association.

Stott, G. N. (1988). Family influence on religious involvement. In D. L. Thomas (Ed.), The Religion and Family Connection: Social Science Perspectives (pp. 258-271). Religious Studies Center: Provo, Utah.

Ulrich, W. L., Richards, P. S., \& Bergin, A. E. (2000). Psychotherapy with Latter-day Saints. In P. S. Richards \& A. E. Bergin (Eds.), Handbook of Psychotherapy and 
Religious Diversity (pp. 185-209). American Psychological Association:

Washington, D. C.

Worthington, E. L. Jr. (1989). Religious faith across the life span: Implications for counseling and research. The counseling Psychologist, 17, 555-612.

Worthington, E. L. Jr., Mazzeo, S. E., \& Canter, D. E. (2005). Forgiveness-promoting approach: helping clients REACH forgiveness through using a longer model that teaches reconciliation. In L. Sperry \& E. P. Shafranske (Ed.), Spiritually Oriented Psychotherapy (pp. 235-257). American Psychological Association: Washington, D. C. 
Table 1

Proportions of participants 2001 MMPI scores within the normal range

\begin{tabular}{lcccccccc}
\hline & Scale 1 & Scale 2 & Scale 3 & Scale 4 & Scale 6 & Scale 7 & Scale 8 & Scale 9 \\
Means & 52.21 & 50.96 & 54.85 & 51.19 & 49.42 & 49.73 & 49.52 & 44.60 \\
\hline S D & 7.89 & 9.25 & 7.24 & 7.06 & 7.71 & 7.21 & 6.26 & 6.02 \\
\hline Proportion & $4 / 52$ & $2 / 52$ & $6 / 52$ & $2 / 52$ & $1 / 52$ & $2 / 52$ & $0 / 52$ & $0 / 52$ \\
in clinical & .072 & .038 & .115 & .038 & .019 & .038 & .000 & .000 \\
Range & & & & & & & & \\
\cline { 1 - 5 } Asymp. Sig & .935 & .270 & .347 & .270 & .106 & .270 & & \\
\hline
\end{tabular}


26

Table 2

Results of the repeated measures ANOVA on MMPI scales over time

\begin{tabular}{|c|c|c|c|c|c|}
\hline MMPI & Year & Mean & SD & F value & p. value \\
\hline \multicolumn{6}{|l|}{ clinical scale } \\
\hline F Scale & 1984 & 55.85 & 5.22 & 91.50 & .000 \\
\hline \multirow[t]{2}{*}{ Infrequency } & 1987 & 53.65 & 3.63 & & \\
\hline & 2001 & 45.02 & 5.38 & & \\
\hline Scale 1 & 1984 & 52.90 & 9.38 & .69 & .504 \\
\hline \multirow[t]{2}{*}{ Hypochondriasis } & 1987 & 51.29 & 9.52 & & \\
\hline & 2001 & 52.35 & 7.89 & & \\
\hline Scale 2 & 1984 & 47.52 & 6.80 & 4.22 & .018 \\
\hline \multirow[t]{2}{*}{ Depression } & 1987 & 50.65 & 7.63 & & \\
\hline & 2001 & 51.31 & 9.52 & & \\
\hline Scale 3 & 1984 & 56.08 & 7.94 & 4.52 & .013 \\
\hline \multirow[t]{2}{*}{ Hysteria } & 1987 & 58.42 & 7.26 & & \\
\hline & 2001 & 55.00 & 7.50 & & \\
\hline Scale 4 & 1984 & 58.50 & 9.84 & 12.10 & .000 \\
\hline Psychopathic & 1987 & 57.98 & 9.12 & & \\
\hline Deviate & 2001 & 51.29 & 7.24 & & \\
\hline Scale 6 & 1984 & 55.25 & 8.47 & 10.70 & .000 \\
\hline \multirow[t]{2}{*}{ Paranoia } & 1987 & 54.75 & 7.26 & & \\
\hline & 2001 & 49.46 & 7.82 & & \\
\hline
\end{tabular}




\begin{tabular}{lccccc} 
Scale 7 & 1984 & 58.40 & 8.02 & 12.95 & .000 \\
Psychasthenia & 1987 & 55.48 & 10.11 & & \\
& 2001 & 50.00 & 7.37 & & .000 \\
\hline Scale 8 & 1984 & 59.77 & 9.03 & 16.77 & \\
Schizophrenia & 1987 & 54.31 & 9.97 & & .000 \\
& 2001 & 49.67 & 6.30 & & \\
\hline Scale 9 & 1984 & 62.88 & 8.70 & .90 .71 & \\
Hypomania & 1987 & 58.06 & 8.31 & & \\
\hline $\mathrm{N}=48 ; \quad \mathrm{df}=2$ & & & & & \\
\hline
\end{tabular}

$\mathrm{N}=48 ; \quad \mathrm{df}=2$ 


\section{Table 3}

Correlations between intrinsic motivations and clinical scales of the MMPI

\begin{tabular}{|c|c|c|c|c|c|c|c|c|c|c|}
\hline & & HS & $\mathrm{D}$ & HY & PD & PA & $\mathrm{PT}$ & SC & MA & $\mathrm{F}$ \\
\hline 1984 & $\begin{array}{l}\text { Intrinsic } \\
\text { Scores }\end{array}$ & .082 & .082 & .126 & -.098 & .094 & .094 & -.170 & .032 & -.148 \\
\hline 1987 & $\begin{array}{l}\text { Intrinsic } \\
\text { Scores }\end{array}$ & .074 & -.009 & .015 & -.323 & .007 & -.167 & -.223 & -.122 & -.132 \\
\hline 2001 & $\begin{array}{l}\text { Intrinsic } \\
\text { Scores }\end{array}$ & -.118 & -.140 & .166 & .078 & -.048 & -.032 & .037 & .081 & -.184 \\
\hline
\end{tabular}


Table 4

Repeated Measures ANOVA for Extrinsic and Intrinsic Scores

\begin{tabular}{lcccc}
\hline & Means & SD & F & Sig. \\
1984 Extrinsic & 23.13 & 5.14 & .974 & .381 \\
1987 Extrinsic & 22.19 & 5.19 & & \\
2001 Extrinsic & 22.77 & 3.95 & & \\
1984 Intrinsic & 38.00 & 4.50 & 1.71 & .187 \\
1987 Intrinsic & 39.32 & 3.64 & & \\
2001 Intrinsic & 38.42 & 4.40 & & \\
\hline $\mathrm{N}=53 \quad \mathrm{df}=2$ & $\mathrm{SD}=$ Standard Deviation & & \\
\hline
\end{tabular}

Formatted: No underline 
Table 5

Relationship between 1984 code types and 2001 code types

\begin{tabular}{|c|c|c|c|c|}
\hline \multirow{5}{*}{$\begin{array}{l}\text { \& } \\
\text { O్ન }\end{array}$} & & \multicolumn{2}{|c|}{2001} & \multirow[b]{2}{*}{ Total } \\
\hline & & Discontinuous & Continuous & \\
\hline & Discontinuous & 4 & 10 & 14 / 27.5\% \\
\hline & Continuous & 6 & 31 & $37 / 72.5 \%$ \\
\hline & Total & $10 / 19.6 \%$ & 41 / 80.4\% & $51 / 100 \%$ \\
\hline
\end{tabular}

